\title{
Gaztagintzako prentsaketa-teknikak: gure arbasoetatik gaur egunera arte
}

Pressing techniques in cheese making: from our ancestors to today

\author{
Jose Miguel Campillo-Robles ${ }^{* 1}$, Ariane Atxa ${ }^{2}$, Laura Telleria ${ }^{2}$, Itxaso Domingo ${ }^{2}$ \\ ${ }^{1} \mathrm{ZTF} / \mathrm{FCT}, \mathrm{UPV} / \mathrm{EHU}$ \\ ${ }^{2}$ Mondragon Unibertsitatea
}

LABURPENA: Mamiaren prentsaketa prozesu garrantzitsua da gaztagintzan. Horri esker, mamiak gazura galtzen du. Berez, gaztaren kontserbazio egokia lortzeko, mamiaren hezetasuna txikitu behar da. Gainera, prentsaketari esker, gaztaren azala eratzen da, eta gaztari forma egokia ematen zaio. Mendeetan zehar, eskuzko prentsaketa erabili izan da gehienbat, baina XIX. mendearen bukaeratik prentsen erabilera zabaldu da. Orain arte erabilitako prentsaketa-teknikak eta tresneria oso gutxi deskribatu dira bibliografian. Hori dela eta, dokumentu honetan gai honi buruz egindako bilaketa-lana aurkezten dugu; zehazki, Euskal Herrian erabili izan diren prentsaketa-teknikak jasota daude, bai eta zeregin horretan erabili diren tresnak ere.

HITZ GAKOAK: gazta, prentsa, gazura, mamia, presioa, gatzagia.

ABSTRACT: The pressing process of curd is very important in cheese making. Pressing helps in the releasing of whey from the curd. Indeed, it is necessary to reduce the humidity of the curd to obtain a good cheese conservation. Moreover, during the pressing, the skin of the cheese is formed and the desired shape is obtained for the cheese. Over the centuries, manual pressing has been largely used. However, since the end of the XIX century, press have been widely used. There is not much information about cheese pressing techniques or tools in the literature. For this reason, we have collected information on this subject, and we present it in this document. Specifically, the cheese pressing techniques used in the Basque Country are explained below, and the tools used in this task too.

KEYWORDS: cheese, press, whey, curd, pressure, rennet.

\footnotetext{
* Harremanetan jartzeko / Corresponding author: Jose Miguel Campillo-Robles. Fisika Aplikatua II saila, Zientzia eta Teknologia Fakultatea (UPV/EHU), Sarriena auzoa z/g, 48940, Leioa, Euskal Herria. - joxemi.campillo@ehu.eus - https://orcid. org/0000-0002-2565-6343.

Nola aipatu / How to cite: Campillo-Robles, Jose Miguel; Atxa, Ariane; Telleria, Laura; Domingo, Itxaso (2019). «Gaztagintzako prentsaketa-teknikak: gure arbasoetatik gaur egunera arte»; Ekaia, 35, 2019, 239-255. (https://doi.org/10.1387/ekaia.19681).

Jasoa: 3 maiatza, 2018; Onartua: 11 urria, 2018.

ISSN 0214-9001 - eISSN 2444-3255 / (c) 2019 UPV/EHU
}

cc)(i) () Obra hau Creative Commons Atribución 4.0 Internacional-en lizentziapean dago 


\section{SARRERA}

Artzaintza Euskal Herriarekin batera sortu zela esatea gehiegizkoa izan daitekeen arren, aspaldiko lanbidea da gurean. Duela 5.000 urte, Pirinioen mendebaldeko gizakiak abereak etxekotzen hasi ziren [1]. Ordutik, artzaintza aberastasun-iturria izan da, eta ez soilik ekonomikoa. Artzainek mota askotako produktuak lortu izan dituzte artaldeetatik: haragia, esnea, larrua, artilea, eta abar. Horien artean esnea azpimarratu behar dugu, likido oso elikagarria delako. Zoritxarrez, esnea oso erraz galtzen da, eta horregatik denbora luzean kontserbatzeko gazta egiten zen. Horrela, euskal artzainek mendeetan zehar gazta ekoitzi dute. Gaztaren ekoizpen tradizionala gure egunetara ailegatu da, ia aldaketarik gabe. Hori dela eta, esan dezakegu duela gutxira arte gaztagintza zientzia baino artisau-lana izan dela. Euskal Herriko artzaintza eta gaztagintza tradizionalaren inguruan ikerketa, liburu eta material asko dago [2-6]. Gaztagintzan erabilitako tresneriaren inguruan informazio zabala dago, baina zehaztu gabeko alderdi batzuk ere badaude. Izan ere, mamiaren prentsaketa-tekniken inguruan nolabaiteko ezagutza badago ere [7], horretarako tresneriaren inguruan ez da ia ezer idatzi.

Gaztaren prentsaketa-prozesuaz arituko gara dokumentu honetan. Hori dela eta, lan honen helburu nagusia Euskal Herrian erabili izan diren teknika eta tresneria tradizionalak era argian azaltzea da. Gai honen inguruan material idatzirik ez dagoenez, informazioa jasotzeko bi motatako bilketalana egin dugu. Alde batetik, han-hemenka erabilitako tresneriaren irudiak jaso ditugu, eta, bestetik, prentsaketa-tekniken inguruko lekukotzak. Gure informazio-iturriak museoak, gaztagileak eta adituak izan dira gehienbat (ikus 1. irudia).

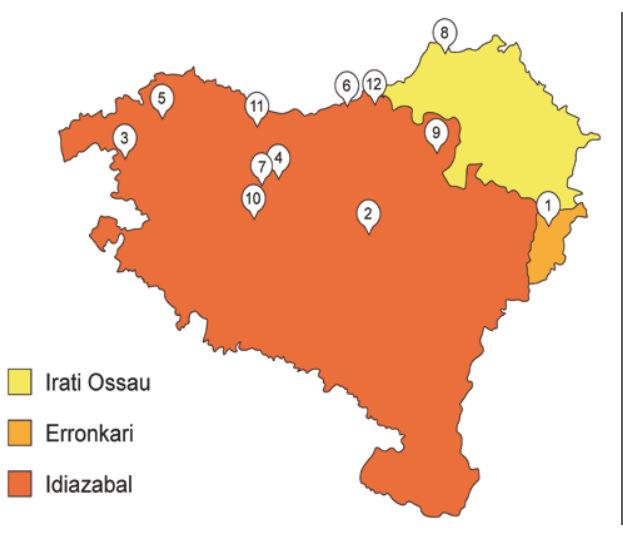

1. Gazta eta Transhumantzia Museoa (Uztarrotze).

2. Iruñeko Erresumaren Museo Etnografikoa (Arteta)

3. Artziniegako Museo Etnografikoa (Artziniega).

4. Erreizabal baserria (Legazpi).

5. Euskal Museoa (Bilbo).

6. San Telmo museoa (Donostia).

7. Gomiztegi artzain-eskola (Oñati).

8. Baionako Euskal Museoa (Baiona)

9. Baztango Museoa (Elizondo).

10. Txurtxil gaztandegia (Larrea, Araba)

11. MILKARSA, (Elgoibar).

12. Ardi SL (Oiartzun).

1. irudia. Euskal Herriko gazten jatorri-izendapenak, eta gaztarekin erlazionaturiko leku esanguratsu batzuk (egilea: A. Atxa). 


\section{HISTORIA PIXKA BAT}

Duela gutxira arte, gaztaren jatorria Historiaurrearen laino zulaezinean egon da ezkutuan. Zorionez, azken hamarkadetan gaztarekin loturiko aurkikuntzei esker argi zipriztin batzuk agertu dira, eta gizakien hastapeneko esperientzien inguruko ezagutza handitzen ari da poliki-poliki [8].

Zalantzarik gabe, gaztaren jatorria abeltzaintzaren garapenarekin loturik dago. Abeltzaintza (eta nekazaritza) Mesopotamian garatu ziren Neolitoan, Harri Aroaren amaieran (K.a. 6000 urte inguruan). Orduan, gizakiak hainbat landare eta animalia etxekotu zituen. Etxekotu ziren animalien artean ahuntzak, ardiak eta behiak zeuden. Antza denez, gizakiak, hasieran ardia eta ahuntza etxekotu zituen, eta geroago behia. Orduko gizakiak animalia horien esnea hartzen zuen, jangarri oso aberatsa zelako, baina beste gauza batzuk ere lortzen zituen: haragia, larrua, artilea, eta abar. Aurkikuntza arkeologikoek frogatu dute aldaketa garrantzitsu hauek geroago ailegatu zirela Euskal Herrira eta Europara.

Gaztaren jatorri zehatza ezezaguna bada ere, ikertzaile gehienek Neolitoaren hasieran kokatzen dute (K.a. 6000 urte inguruan). Tigris eta Eufrates ibaien arteko lurraldean hasi omen zen gaztaren ekoizpena, Ilgora Emankorra deiturikoan. Dena dela, gaztagintzako aztarnarik zaharrenak Ipar Europan topatu dituzte. Aurkitutako lehenengo aztarnak ontzigintzaren sorrerarekin loturik daude. Izan ere, K.a. 5500 urte inguruan gazta egiteko erabiltzen ziren hainbat pieza aurkitu dira Poloniako Kujavia eskualdean [9]. Pieza horiek zeramikazkoak ziren, eta zuloak zituzten gazura drainatzeko. Euskal Herriko gaztanontzi zaharrenak, berriz, La Hoyako aztarnategian (Araba) topatu dira. Duela 3.000 urte inguruko buztinezko gaztanontziak dira, 12-15 cm-ko diametrodunak [10].

Gaztagintzako lehenengo lekukotza K.a. 3100-3500 urte arteko friso sumertar bat da. Friso hori Irakeko museo nazionalean dago, Bagdaden. Bertan, esnearen hainbat prozesu deskribatzen dira. Geroago, K.a. 2000 urte inguruan, Egiptoko hilobietako horma-irudietan gazta egiteko prozesua azaltzen da, eta baita sumertar zibilizazioko idazki kuneiformeetan ere. Hala ere, antzinaroko gaztagintzako deskribapen osatuena Erromako soldadu batek egin zuen. Deskribapen hori L.J.M. Columella-ren De Re Rustica nekazaritza-tratatuan dago (K.a. 50. urtea). Kontserbatutako gaztarik zaharrena, aldiz, Txinako Xinjiang probintziako Taklamakan basamortuan aurkitu zuten (K.a. 1615 urtea).

\section{GAZTA}

Gazta produktu fresko edo ondua da, solidoa edo erdi solidoa. Gaztak hainbat jatorri izan ditzake: esnea (osoa, partzialki gaingabetua edo guz- 
tiz gaingabetua), esne-gaina, gurinaren gazura edo horietariko batzuen edo guztien nahasketa. Jatorrizko produktu horiek guztiz edo partzialki koagulatzen dira, gatzagiaren edo beste koagulatzaile egoki batzuen bitartez, gazta lortzeko. Gaztagintzan, batzuetan, gazura partzialki kentzen da, eta, beste batzuetan ez. Bestalde, gazta batzuetan, laktosaren hidrolisia egiten da aurretik. Gaztetan, beti, kaseina eta gazuraren proteinen arteko erlazioak esnearenaren berdina edo handiagoa izan behar du [11]. Gazta esnearen proteinaz eta koipeaz osaturik dago, baina badauka kaltzio eta fosforo asko ere. Mota askotako zapore, testura eta formetan ekoizten da munduan zehar.

Berez, gazta munduan gehien jaten den elikagaietariko bat da. Munduan, urteroko gazta-ekoizpena 19-23 × $10^{6}$ tonen inguruan dagoela jotzen da [12, 13]. Azken 30 urteetan, kopuru hori $\% 4$ handitu da urtez urte [12]. Munduko ekoizlerik handiena Europa da, $\sim 11 \times 10^{6}$ gazta tonarekin [12].

Munduko gazten artean aniztasun handia dago, eta zaila da sailkapen sistematiko bat egitea. Gazta gehienek tokian tokiko ezaugarriak dituzte, eta asko ekoizpen txikikoak dira. Hori dela eta, ez da erraza munduan zenbat gazta mota ekoizten diren zehaztea. Adibidez, 1970ean, Sandine eta Elliker-ek munduan 1.000 gazta mota daudela baieztatu zuten [13]. Geroago, 1972an, Walter eta Hargrove-k 400 gazta mota deskribatu zituzten, eta beste 400 zerrendatu [14]. 1981ean, Burkhalter-ek prestatutako katalogoan 510 gazta mota ageri dira [15]. Azkenik, 2009an, Harbutt-ek 750 gazta mota inguru deskribatu zituen bere liburuan [16]. Berez, munduan gehien jaten diren gazta motak honako hauek dira: cheddar, mozzarella, gouda, emmental eta camembert [17].

Gaztak sailkatzeko irizpide bat esnearen jatorria izan daiteke. Berez, munduko esne-ekoizpena honela banatzen da: \% 85 behia, \% 11 ur-bufaloa, $\% 2$ ardia eta $\% 1,5$ ahuntza [12]. Esne guzti horretatik \% 35 gutxi gorabehera erabiltzen da gazta egiteko [12]. Hortaz, munduko gazta-ekoizpen gehiena behi-esnearekin egiten da. Hala ere, hainbat eskualdetan beste esneek garrantzi handiagoa eduki dezakete. Euskal Herrian, adibidez, gazta gehienak ardi-esnez egiten dira. Gazta normalean espezie bakarreko esnearekin ekoizten bada ere, batzuetan hainbat espezietako esneak nahasten dira gazta egiteko.

Gaztak sailkatzeko beste irizpide bat haien ekoizpen-prozesuarekin loturik dago. Gazta mota batzuetan, bakterioen hartzidura erabiltzen da. Hau da, bakterioek esnearen laktosa eraldatzen dute azido laktikoa sortzeko. Azido laktikoak pH-a jaisten du. Horrela, $\mathrm{pH}$-aren balioa 4,6 inguruan dagoenean, esnearen proteina garrantzitsuenak, kaseinak, koagulatzen dira. Munduko gazta-ekoizpenaren \% 22 honela lortzen da [12]. Beste gazta mota batzuetan, berriz, entzimak erabiltzen dira kaseinak koagulatzeko. Entzima horiek gatzagian daude. Gatzagia animalien urdailetik ateratzen 
da normalean, baina hainbat landaretatik eta artifizialki ere lor daiteke. Era horretako ekoizpena munduko gazta-ekoizpenaren $\% 75$ da [12].

Gaztak sailkatzeko erabil daitekeen beste irizpide garrantzitsua ontzeprozesua da [11]. Gazten sailkapen hauek eta beste batzuk 1. taulan ageri dira.

1. taula. Gazten sailkapena lau irizpideren arabera.

\begin{tabular}{l|l|l|l}
\hline \multicolumn{1}{c|}{ Ontze-prozesua [11] } & \multicolumn{1}{c|}{ Koipe-edukia [18] } & \multicolumn{1}{c}{ Azala } & \multicolumn{1}{c}{ Ketua } \\
\hline $\begin{array}{l}\text { Gazta freskoa/berria } \\
\text { (ur-edukia: \% 60-80) }\end{array}$ & Estrakoipetsuak ( \% 60) & Gogorra & Ketua \\
\hline Gazta zuri pasteurizatua & Koipetsuak (\% 45-60) & Biguna & Ketu gabekoa \\
\hline $\begin{array}{l}\text { Gazta ondua: } \\
\text { - Gazta samurra } \\
\text { - Gazta erdi ondua } \\
\text { - Gazta ondua } \\
\text { - Gazta zaharra } \\
\text { - Urteko gazta }\end{array}$ & Erdi koipetsuak (\% 25-45) & Lizunduna & \\
\hline Gazta ondua lizunekin & Erdigaingabetuak (\% 10-15) & Azalik gabeak & \\
\hline & Gaingabetuak (\% 10) & & \\
\hline
\end{tabular}

Gaur egun, mundu mailan ezagunak diren hainbat gazta egiten dira Euskal Herrian. Izatez, jatorri-izendapena duten hiru gazta daude (ikus 1. irudia): Idiazabal, Erronkari eta Ossau-Irati. Hirurak tokiko ardien esne gordinez egindako gaztak dira. Baina, historian zehar, mota askotako gaztak egin dira gurean (adibidez, Auñamendi entziklopediaren arabera 16 ardi-gazta klase ekoitzi izan dira Euskal Herrian [19]). Zoritxarrez, leku askotan gertatu den moduan, hemen ere aberastasun handi hori galdu egin dugu neurri handi batean. Duela gutxi zendutako Ramon Lizeaga gaztagilearen berreskuratze-lana azpimarratu behar dugu bereziki. Euskal Herriko aberastasun galdu hori berreskuratzen saiatu zen. Horrela, antzinako errezetak eta sistema tradizionalak erabiliz, galdutako zortzi gazta-aldaera ekoitzi zituen [20].

\section{GAZTA EGITEKO PROZESUA ETA PRENTSAKETA}

Gazta mota bakoitzak ekoizpen-prozesu propioa badauka ere, prozesu guztiek antzekoak diren ezaugarriak dituzte. 2. irudiak gatzagiaren bidezko gaztagintzako prozesua erakusten du. Gazta egiteko lehenengo urratsa esnea 
jetzi edo eraistea da. Esnea zuzenean erabiltzen ez bada, leku garbi eta hotz batean (normalean $10{ }^{\circ} \mathrm{C}$ azpitik) gorde behar da. Gazta egiten hasteko, esnea berotu behar da, eta ondoren gatzagia gehitzen da. Aurretik esan bezala, gatzagia animalien urdailetik atera ohi da, baina hainbat landaretatik eta artifizialki ere lor daiteke. Gatzagiaren entzimek esnearen proteinak koagulatzen dituzte, eta horrela, mamia edo gatzatua sortzen da. Mamitze-prozesuaren denbora eta tenperatura gazta-motaren araberakoa da. Esnea gatzatu ondoren, zati txikitan mozten da barrutik gazura errazago kentzeko. Gazur asko kendu nahi izanez gero, mamia zati txikiagotan moztu behar da. Zati txikietan moztutako mamia berotu, eta, aldi berean, mugiarazten da. Ondoren, mamia zapi batean bildu eta gaztanontzi batean sartzen da, gero prentsatua izateko. Horren ostean, gazta gazitzen da gatzunean sartuz. Amaieran, gaztaren ontze-prozesua gertatzen da. Gaztaren arabera, ontze-prozesua baldintza berezietan gauzatu daiteke (hezetasuna, tenperatura eta abar).

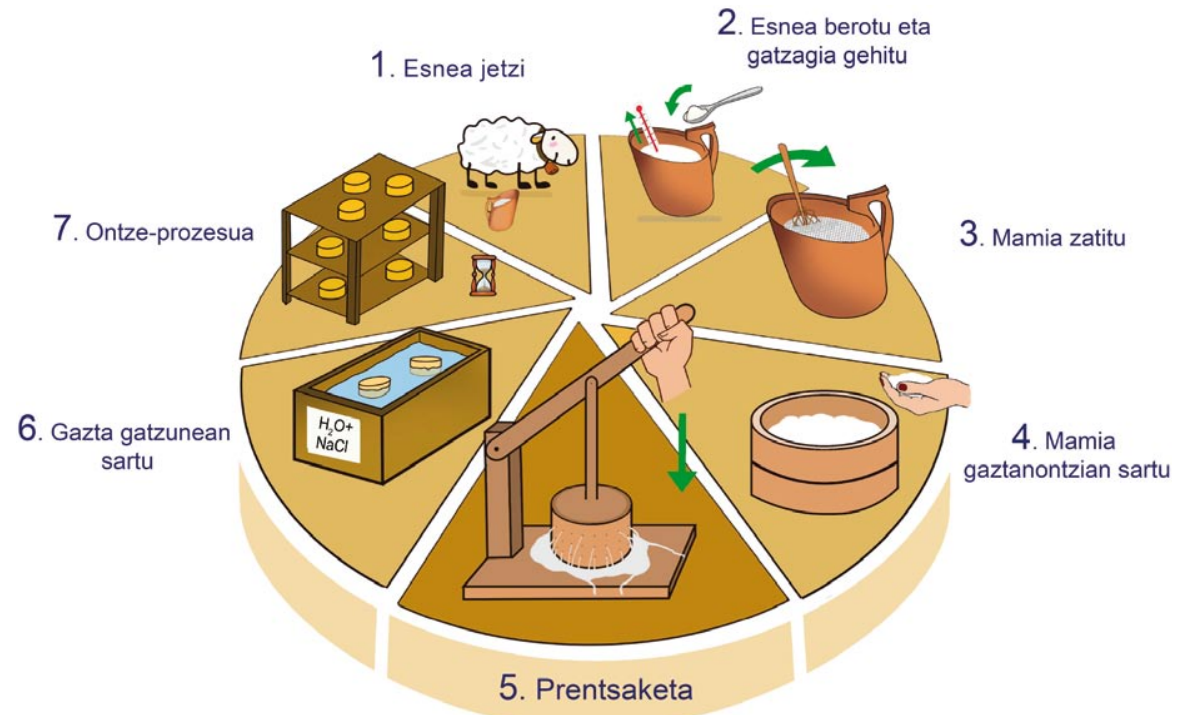

2. irudia. Gatzagiaren bidezko gaztagintzako prozesu orokorra (Egilea: Laura Telleria).

Mamiaren prentsaketaren helburu nagusia gazura kentzea bada ere, zeharka beste bi prozesuetan ere laguntzen du. Alde batetik, gaztaren azalaren eraketa-prozesua prentsaketan hasten da, jarraitzen du gatzunean sartzean eta ontze-ganberan amaitzen da. Beste aldetik, mamia gaztanontzian prentsatzean, gaztari forma ematen diogu.

Gaztan lortu nahi ditugun ezaugarrien arabera prentsaketa-prozesua aldatzen da. Adibidez, gazta freskoek hezetasun handikoak dira, eta ez dute 
gazur asko galdu behar. Berriz, azal gogorreko gaztek hezetasun gutxi daukate, eta horrek eskatzen du prentsaketan gazur gehiago galtzea. Bestalde, prentsaketa-prozesuan presioa gradualki handitu behar da [7]. Hau da, hastapenean mamiaren gaineko presioa handiegia bada, azaleko poroak azkarregi ixten dira (azalaren eraketa), eta gazuraren irteera oztopatzen da.

Garai batean, gazta prentsatzerakoan irteten zen gazura txerriak eta bestelako animaliak gizentzeko erabiltzen zen. Hala ere, gazura ez da egokia ardiak elikatzeko; izan ere, hala, esnea edateari ekin leizaiokete. Baina hori ez da gazuraren erabilera bakarra. Izan ere, gazuretik gaztanbera ere ekoitz daiteke. Gazura aprobetxatzen duten artzain gutxi batzuk badaude ere, gehienek ez diote balio handirik ematen, eta bota egiten dute [21]. Berez, gazura ezin da edozein lekutara bota, isurkari kutsakorra delako. Zoritxarrez, gaur egun gazurak gaztandegien inguruko zelai edo erreketan amaitzen du. Hori dela eta, horren gaineko kontrola handitzeko beharra dago.

\section{GAZTANONTZIAK}

Esan bezala, mamiaren prentsaketaren bitartez gaztaren azala eta forma definitzen dira. Horretarako, prentsaketa-prozesuan zehar mamiari eutsiko dioten ontziak ezinbestekoak dira, gaztanontziak, alegia. Gaztanontziak molde zulodunak izaten dira, presioa egitean gazurari irteten uzten diotenak. Haien forma eta dimentsioak gazta mota bakoitzari lotuak egon ohi dira. Adibidez, Idiazabal gaztaren altuerak 8 eta $12 \mathrm{~cm}$ artean egon behar $\mathrm{du}$, eta diametroak, 10 eta $30 \mathrm{~cm}$ artean.

Gure egunetara ailegatu diren lehen gaztanontziak zeramikazkoak dira (ikus 3.a) irudia). Horrek ez du esan nahi bestelakoak erabiltzen ez zirenik. Egia esateko, historian zehar, mota askotako materialak erabili izan dira gaztanontziak fabrikatzeko. Euskal Herrian gehienbat egurrezko gaztanontziak (pagoa, haritza, gaztainondoa, eta abar) erabili izan dira: gazta-azala eta zumitza deiturikoak.

Gazta-azala egurrezko eraztun malgu bat da, zuhaitzen azalekin egindakoa (hortixe datorkio izena). Molde mota honek gazta ezartzeko beste tresna baten beharra dauka, ez baitu oinarririk (ikus 3. b) irudia).

Zumitzak molde zilindrikoak dira, eta mota desberdinetako oinarriak izan ditzakete. Saskiak egiteko erabiltzen den teknikarekin egindako zumitz oinarridunak daude (ikus 3. c) irudia). Horiek gehienetan uretan bigundutako gaztainondoz eginak izan dira. Bestalde, egurrezko erliebedun hondoak dituzten zumitzak ere badaude, gaztetan irudi edergarriak sortzeko erabili izan direnak (ikus 3. d) irudia). 
Jose Miguel Campillo-Robles, Ariane Atxa, Laura Telleria, Itxaso Domingo

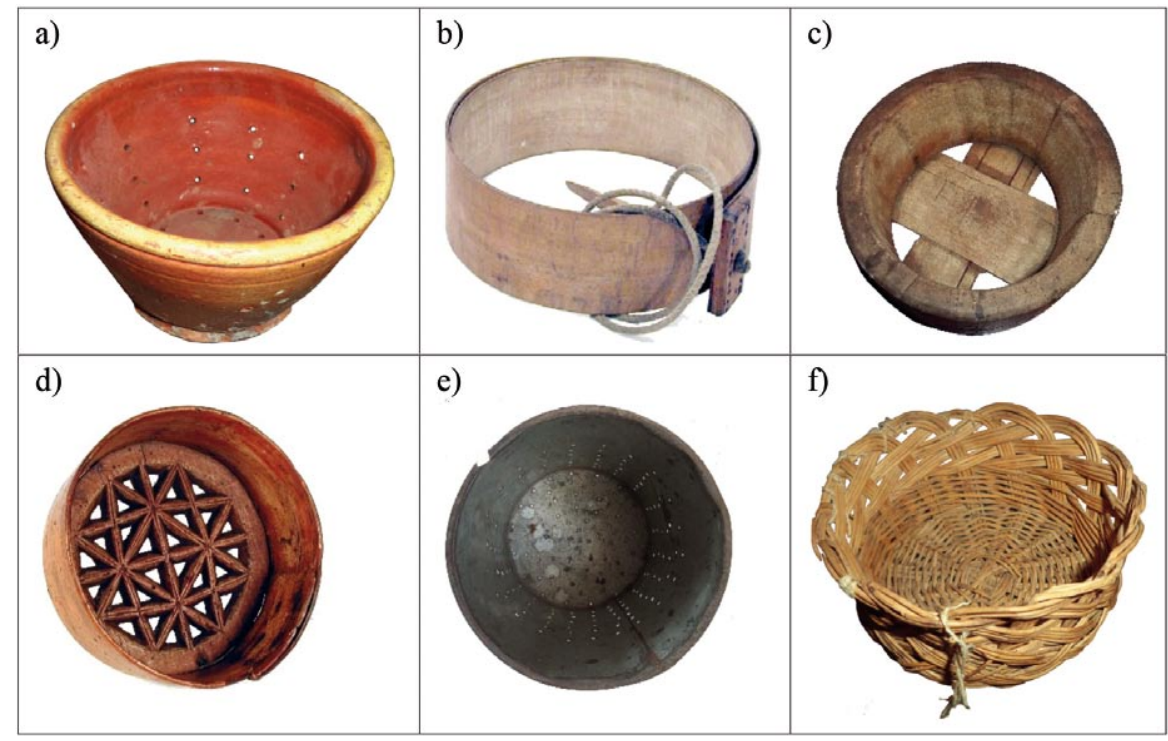

3. irudia. Gaztanontziak: a) zeramikazkoa, b) gazta-azala, c) eta d) zumitzak, e) metalezkoa eta f) gazta freskoarena. (Iturriak: a), e) eta f) Artziniegako Museoa eta Artea Etnografi Elkartea (Artziniega), b) Baionako Euskal Museoa, c) Erreizabal baserria-Artzaintzaren Ekomuseoa (Legazpi), d) (C) San Telmo Museoa (Donostia).

Egurrezko gaztanontziak erabiltzeaz gain, metalezkoak ere sarritan erabili izan dira Euskal Herrian (ikus 3. e) irudia). Gainera, gazta freskoa egiteko, zumezko gaztanontziak erabili izan dira (ikus 3. f) irudia).

\section{ESKUZKO PRENTSAKETA}

Ikusi dugun moduan, gazta hobeto kontserbatzeko mamiaren hezetasuna txikitu behar da. Mendeetan zehar, eskuak erabili izan dira mamiari gazura kentzeko (eskuzko prentsaketa). Teknika hori ondo dokumentatuta dago historian zehar. Adibidez, Columella soldadu erromatarrak laburki azaltzen du eskuzko prentsaketa (manu pressum) K.a. 50. urteko bere nekazaritza-tratatuan [22].

Eskuzko prentsaketa egiten den bitartean, gaztari forma ere eman behar zaio. Hori dela eta, aurretik aipatutako gaztanontziak erabiltzen ziren. Teknika hau mundu guztian zehar erabili izan da mendeetan zehar, eta gure egunetara ailegatu da, adibidez, Erronkariko ibarrean. Euskal Herrian, eskuzko prentsaketa egiteko bi modu egon dira, gaztanontzien arabera. 


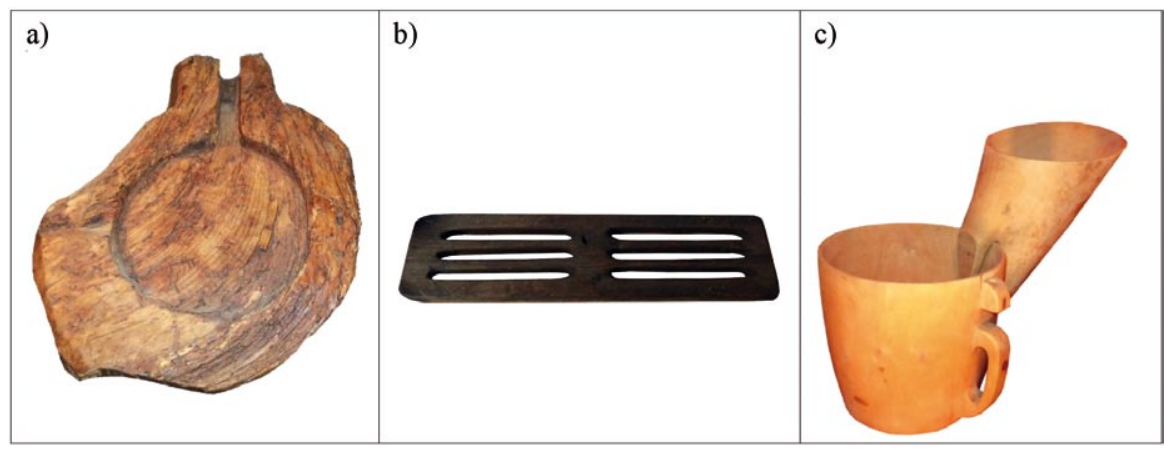

4. irudia. Eskuzko prentsaketan erabilitako hainbat tresna: a) zortzea, b) txurka/ kartola eta c) abatza eta iragazkia. (Iturriak: a) eta c) Iruñeko Erresumaren Museo Etnografikoa (Arteta) eta b) Idiazabal Gaztaren Interpretazio Zentroa (Idiazabal)).

Gazta-azala erabiltzeko ohitura izan duten lekuetan (adibidez, Erronkariko ibarrean), egurrezko azpil bat erabili izan dute gazura jasotzeko eta bideratzeko, zortze izenekoa (ikus 4. a) irudia). Horrela, gazta-azala zortzearen gainean jartzen zuten, eta ondoren mamia sartzen zuten. Jarraian, artzainek mamia eskuekin sakatzen zuten (ikus 5. irudia), eta, gazura irteten zen neurrian, presioa handitzen zuten. Bestalde, gazura errazago irten zedin, mamiaren erdiko partean zuloak egiten ziren, zizpitea izeneko burdinazko hagatxo bat erabiliz. Teknika hori batez ere Pirinio inguruan egon da zabalduta, eta horren inguruko lekukotzak Kataluniaraino iristen dira.

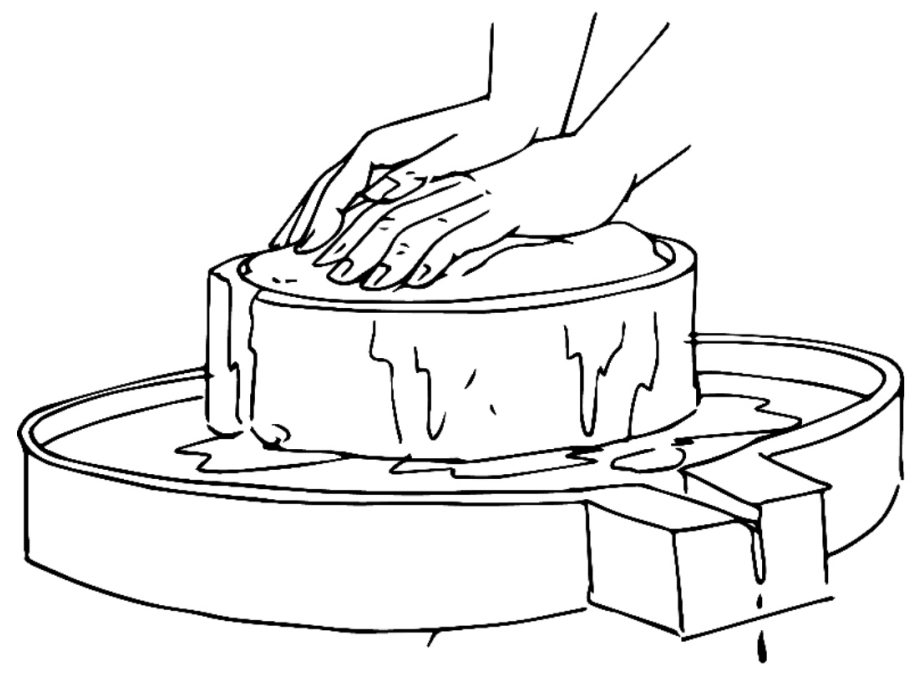

5. irudia. Mamiaren eskuzko prentsaketa gazta-azala eta zortzearekin (Egilea: Itxaso Domingo). 
Euskal Herriko beste zenbait tokitan, zumitza, txurka/kartola eta abatza erabili izan dira mamiaren eskuzko prentsaketan (ikus 4. b) eta c) irudiak). Artzainek zumitzaren azpian txurka/kartola izeneko ohol luze eta zuloduna jartzen zuten, ondoren gazura abatzean jasotzeko (ikus 6. irudia). Adibidez, Kreta uharteko mendietan antzeko teknika eta tresneriak erabili izan dituzte gazta prentsatzeko [23].

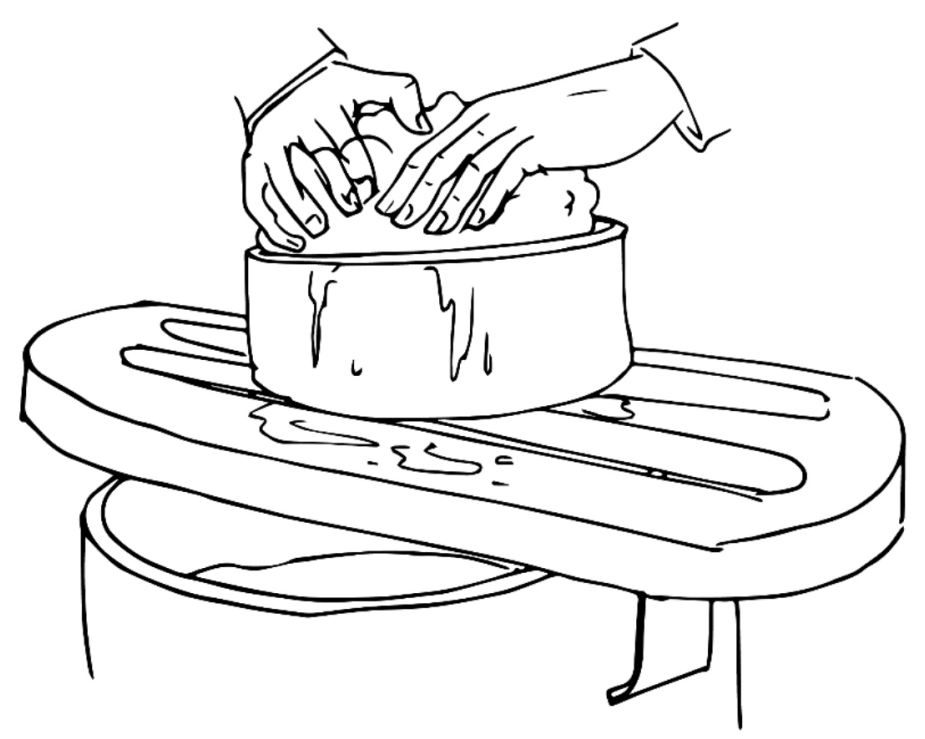

6. irudia. Mamiaren eskuzko prentsaketa zumitza, txurka/kartola eta abatzaren bidez (Egilea: Itxaso Domingo).

Eskuekin mamiari eragitea lan nekeza eta gogorra da; horregatik, artzain batzuek arazoak izan dituzte eskuetan. Batzuetan, artzainek egurrezko estalki bat lantzen zuten, gaztanontzia estali eta indarra eragiteko prozesua errazteko. Beste batzuetan, harriak erabili izan dira gazta egiteko prozesuan, presioa luzaroan mantentzeko helburuarekin. Harrien pisuari esker, presio konstantea mantentzen da nahi dugun denboran, eta, horrela, mamiak poliki-poliki gazura askatzen du. Berez, mamiaren gaineko presioa progresiboki handitu behar da [7]. Hasieran, mamiaren gaineko presioa oso handia bada, azala azkarregi eratzen da (poroak itxi), eta horrek gazuraren irteera oztopatzen du. Hori dela eta, harriak progresiboki aldatu behar dira. Prentsaketa pisu txikiko harri batekin hasi behar da, eta, gero, pisu handiagoko beste harri batzuekin jarraitu. 


\section{PRENTSA TRADIZIONALAK}

Mamiaren eskuzko prentsaketak mendeetan zehar iraun du. Alabaina, prentsaketa-prozesua errazteko, halako batean artzainak prentsak erabiltzen hasi ziren. Zoritxarrez, gaur egun ez dakigu zehaztasunez noiz hasi ziren. Egia esateko, lekuaren araberako kontu bat dela ematen du, baina esan daiteke prentsen erabilera XIX. mendearen bukaeran eta XX. mendearen hasieran abiatu zela.

Artikuluaren atal honetan Euskal Herrian erabili izan diren prentsa tradizionalak deskribatuko ditugu: palankadun eta torlojudun prentsak. Prentsa tradizional hauek guztiak egurrezkoak dira, eta ez dago prentsa estandarrik. Hau da, ezaugarri antzekoak badituzte ere, prentsa guztiak desberdinak dira. Guztiek artisau-diseinua daukate, artzainek edo ingurukoek eraiki dituzte eskura zeuzkaten baliabideak erabiliz.

\subsection{Palankadun prentsak}

Euskal Herrian gehien erabili den prentsak palanka mekanismo baten bidez lan egiten du. Era honetako prentsak oso sinpleak dira, eta, horregatik, oso zabalduta daude munduan zehar ere. Egurrezkoak dira osorik, edo ia osorik. Eskegitako zamaren indarra 2-3 aldiz biderkatzen dute (diseinuaren dimentsioen arabera). Esan bezala, ez dago palankadun prentsa estandarrik. Gehienak antzekoak dira, baina guztiak desberdinak dira. 7. irudian holako hiru prentsa ikus daitezke.

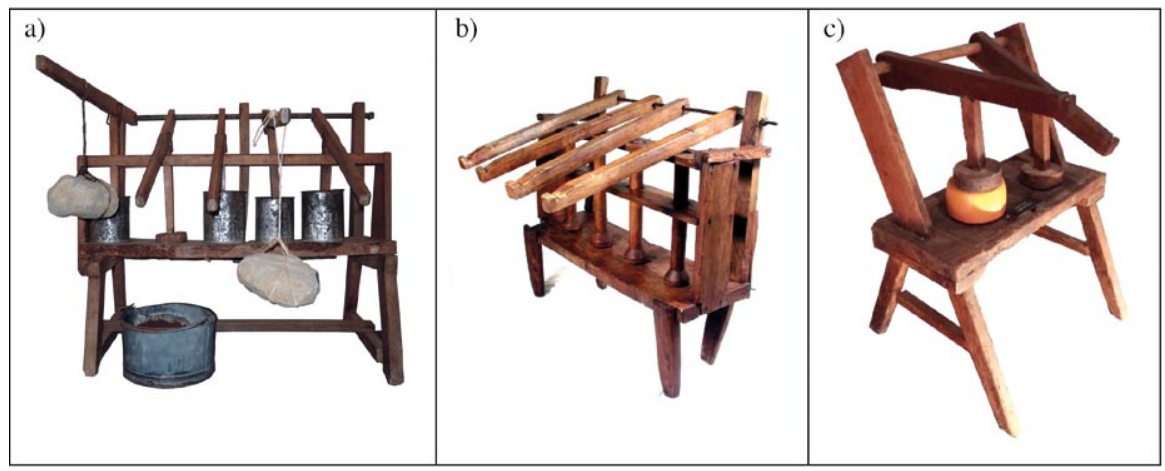

7. irudia. Palankadun prentsak. (Iturriak: a) Artziniegako Museoa eta Artea Etnografi Elkartea (Artziniega), b) (C) San Telmo Museoa (Donostia) eta c) Erreizabal baserria-Artzaintzaren Ekomuseoa (Legazpi)).

Prentsa mota hau erabiltzeko bi modu daude. Palankadun prentsa batzuetan, egurrezko besoaren muturrean koska bakarra dago. Bertatik zama/ 
harria eskegitzen da mamia sakatzeko. Hasieran, zama txiki bat jartzen da, eta, ondoren, masa handiagoko beste batzuk (ikus 8. a) irudia). Beste palankadun prentsetan, aldiz, besoaren luzeran zehar hainbat koska daude. Horrela, zama berdina eskegitzen da; hasieran, besoaren biraketa-ardatzetik hurbilago, eta gazura ateratzen den neurrian, kanpoko kosketara urruntzen da, eragindako presioa handituz (ikus 8. b) irudia).

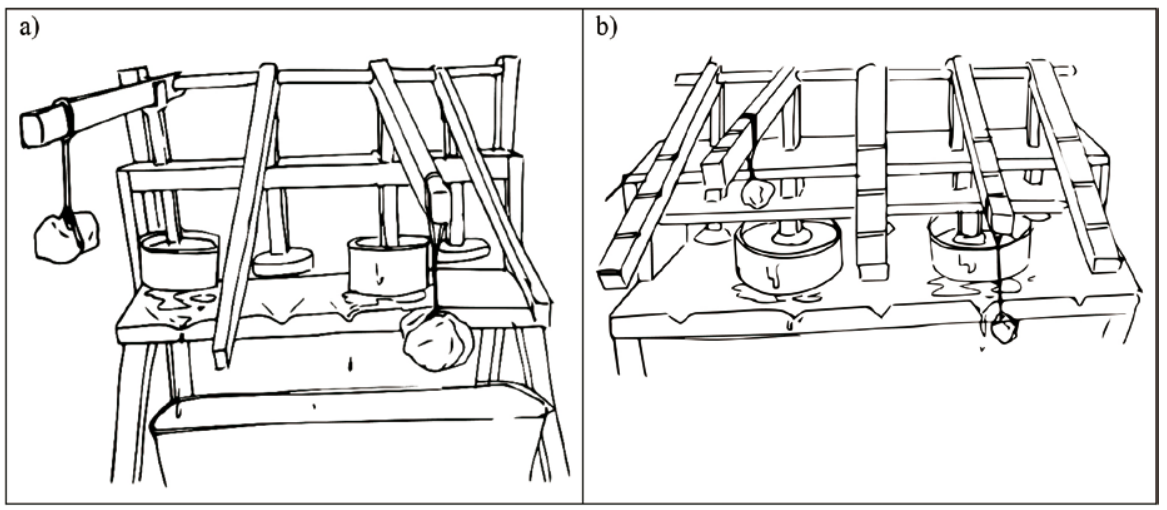

8. irudia. Palankadun prentsaren bi funtzionamenduak: a) zama desberdineko harriak besoaren muturrean eta $\mathrm{b}$ ) harri berdina besoaren koska desberdinetan (Egilea: Itxaso Domingo).

\subsection{Torlojudun prentsak}

Euskal Herrian gehien erabili diren prentsak palankadunak badira ere, torlojuak erabiltzen dituzten prentsa batzuk ere eraiki eta erabili izan dira. Torlojudun prentsak ere egurrezkoak dira, baina batzuetan metalezko piezak ere izaten dituzte. Prentsa hauek normalean bi torloju izan ohi dituzte, eta horiei esker, eragin beharreko indarra txikia izaten da (ikus 9 a) eta b) irudiak). Hala ere, torloju bakarreko prentsak ere badaude (ikus 9 c) irudia).

Torlojudun prentsek aipatu beharreko arazo bat daukate. Mamitik gazura ateratzen den heinean, torlojuek eragindako presioa txikituz doa; eta horregatik, behin eta berriro estutu behar dira. Gainera, presioaren kontrola ez da oso zehatza. Zama erabiltzen duten prentsek beti presio berdina eragiten dute; torlojudunetan, berriz, presioa estutzen dugunaren arabera aldatzen da. 


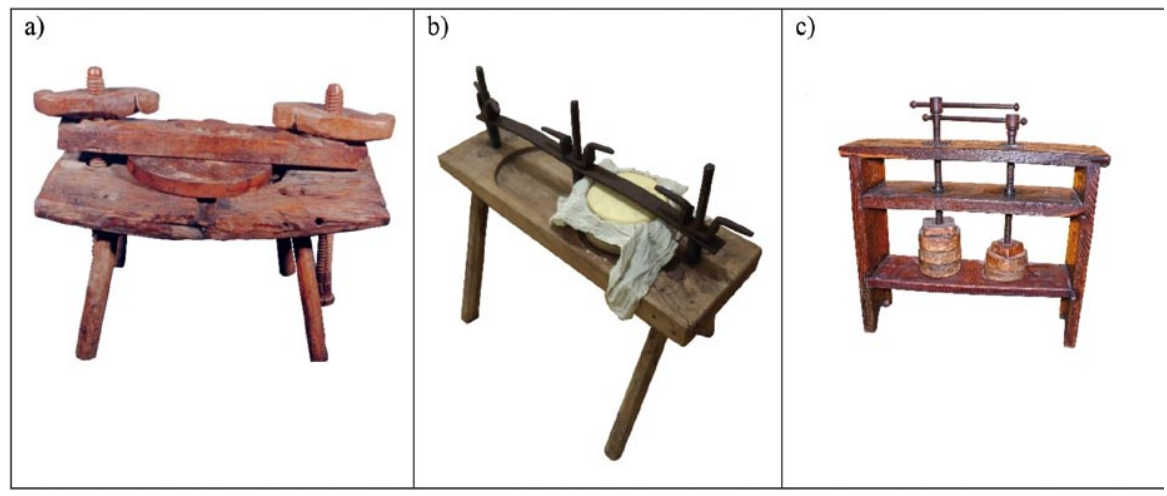

9. irudia. Torlojudun prentsak. (Iturriak: a) Euskal Museoa (Bilbo), b) Gaztaren Interpretazio Zentroa (Idiazabal) eta c) Baztango Museoa (Baztan), argazkiaren egilea: Pello Iriarte).

\section{PRENTSAKETA MODERNOA}

Gaur egungo gaztagintzan (gaztagintza modernoan) bi ekoizpen-eredu daude: alde batetik, oraindik ere gaztagintza tradizionalean aritzen direnak, eta, beste alde batetik, ekoizpen industrialean aritzen direnak.

\subsection{Gaztagintza tradizionala}

Gaur egun gaztagintza tradizionalean aritzen direnek ez dituzte ekoizpen-metodoak asko aldatu. Hori bai, tresneria gaurkotu egin dute. Aspaldian erabilitako tresneria gehiena egurrezkoa zen. Gaur egun, Hego Euskal Herrian debekatuta dago gaztagintzan egurrezko tresneria erabiltzea. Hori dela eta, tresnak metalikoak edo plastikozkoak dira. Adibidez, gaztanontziak plastikozkoak edo altzairu herdoilgaitzezkoak dira. Egia esateko, abantaila bat da. Izan ere, tresnek gehiago irauten dute, eta, gainera, garbitzeko errazagoak direnez, mikroorganismoen ugaltzea oztopatzen da.

Gaztagintza tradizionaleko prentsa modernoak metalikoak dira (aluminiozkoak edo altzairu herdoilgaitzezkoak), aspaldikoak ez bezala. Prentsen gaurkotzean, ekoizpen-gaitasuna handitzea izan da helburu nagusia. Prentsa modernoetan, gaztak multzoka jartzen dira, horizontalki edo bertikalki, eta aldi berean prentsatzen dira. Adibidez, Xx. mendearen bukaeran, malgukidun prentsak hedatu ziren Euskal Herrian. Holako prentsetan, malguki baten konpresioak sortzen du mamiari eragin beharreko presioa (ikus 10 a) irudia). Hala ere, gaur egun artzainen lana errazteko gehienbat aire konprimatuarekin funtzionatzen duten prentsak erabiltzen dira (prentsa pneumatikoak), edo olioarekin dabiltzanak (prentsa hidraulikoak). $10 \mathrm{~b}$ ) irudian, prentsa pneumatiko bat dakusagu. 
Jose Miguel Campillo-Robles, Ariane Atxa, Laura Telleria, Itxaso Domingo

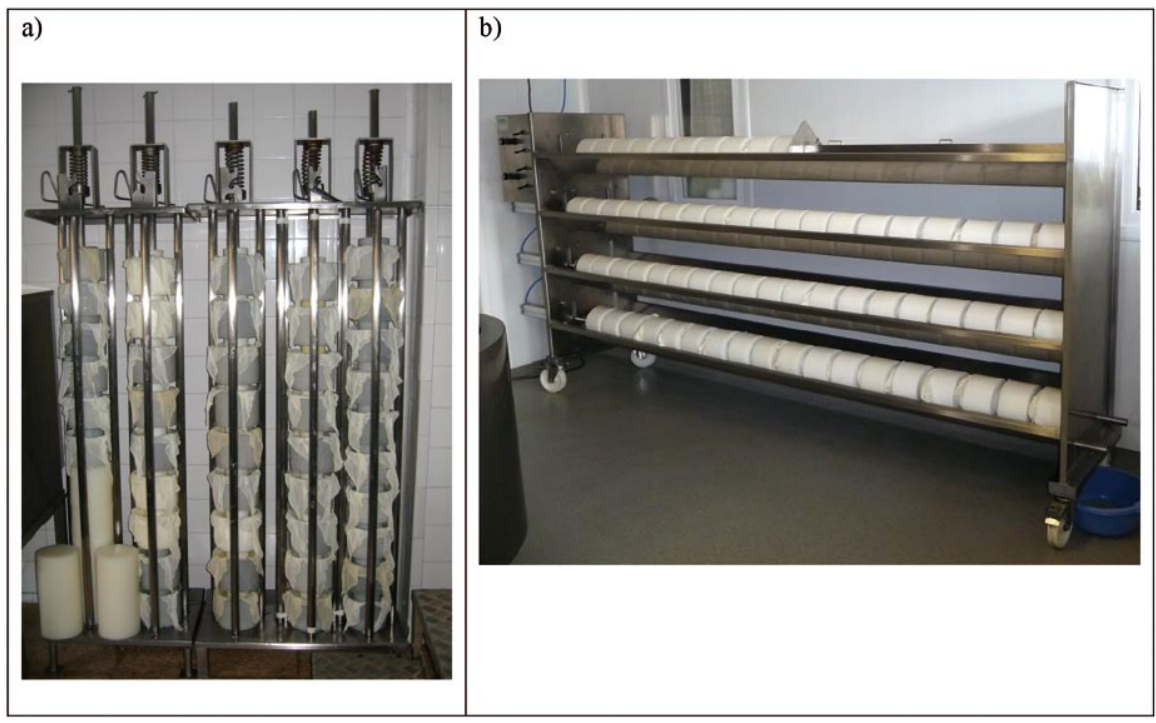

10. irudia. Gaztagintza tradizionaleko prentsa modernoak: a) malgukiduna eta b) pneumatikoa. (Iturriak: a) Txurtxil gaztandegia (Larrea, Araba) eta b) ARDI S. L. (Oiartzun).

Gaztagintza modernoan ekoizpen-parametroen kontrola askoz zorrotzagoa da (tenperatura, hezetasuna, denbora, $\mathrm{pH}-\mathrm{a}$, eta abar). Hori dela eta, prentsa modernoetan presioaren gaineko kontrola handiagoa da. Esan bezala, hasieran presio txikia eragiten da, 1 bar ingurukoa, eta, gazura galtzen duen heinean, handitu egiten da, 2 barreraino.

\subsection{Gaztagintza industriala}

XIX. mendearen erdialdean gaztaren eskakizuna gero eta handiagoa zenez, munduan gaztagintza industriala abiatu zen. AEBko lehenengo gazta-faktoria $1851 \mathrm{n}$ ireki zen Roma-n (New York), eta Europan 1870ean Longford-en (Derbyshire, Ingalaterra) [22]. Euskal Herrian, aldiz, iraultza industrialak ia ez zuen eraginik izan gaztaren ekoizpen-prozesuan. Geroago abiatu zen gaztaren ekoizpen industriala gurean, 1960-80ko hamarkadetan, alegia. Ordutik, gaztagintzako zientzia eta teknologia ikaragarri garatu dira [22, 24, 25].

Gaztaren ekoizpen industrialean, prozesu batzuk (edo guztiak) automatizatzen dira. Horrela, gizakiaren lana murriztu egiten da, eta parametroen kontrola guztiz automatikoa da (tenperatura, presioa, hezetasuna, denbora...). Adibidez, 11. irudiko gazta-prentsa pneumatikoa automatikoa da; hau da, mamiz beteriko gaztanontziak automatikoki sartzen dira pren- 
tsan inolako manipulaziorik gabe. Prentsa horretan, konkretuki 500 g-ko 800 gazta sartzen dira prentsaketa bakoitzean, eta 30 minutu egoten dira prentsatzen (denbora alda daiteke).

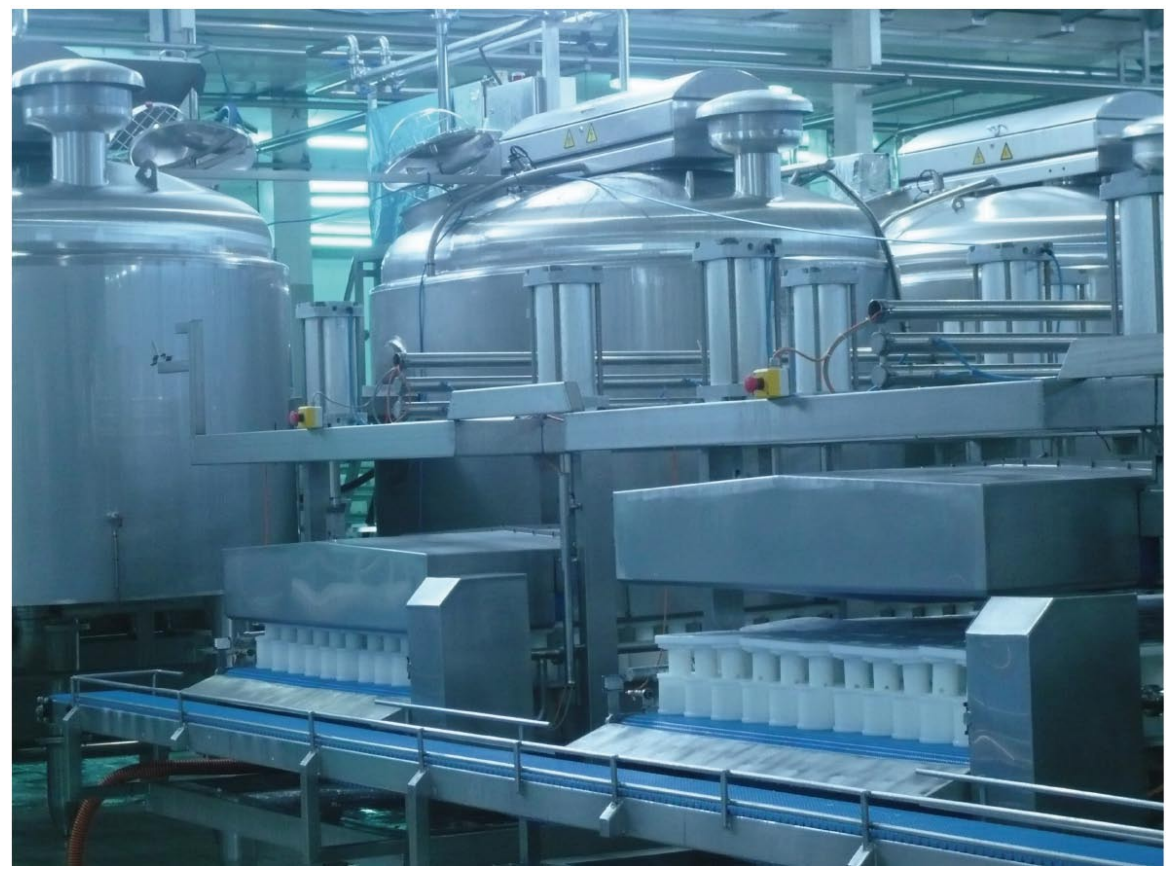

11. irudia. Gazta-ekoizpen industrialean erabiltzen den prentsa pneumatikoa (Iturria: MILKARSA (Elgoibar)).

\section{ONDORIOAK}

Euskal Herriko gaztagintza tradizionalaren inguruan asko idatzi da, gure ekonomian eduki duen garrantziaren seinale. Zoritxarrez, gaztagintza tradizionalean erabilitako prentsaketa-teknikei eta tresnei ez zaie arreta berezirik jarri. Hori dela eta, horren inguruko informazio gutxi eta sakabanatuta dago. Hainbat museotan pieza solteak aurki daitezke, baina ez dago azterketa sistematikorik. Dokumentu honetan Euskal Herrian erabili izan diren prentsatze-tekniken eta horiekin loturiko tresneriaren gainbegirada aurkeztu dugu.

Euskal Herrian, mota askotako prentsatze-sistemak erabili izan dira gazta era tradizionalean ekoizteko. Mendeetan prentsaketa eskuz egin izan da gurean, eta oraindik ere leku askotan erabiltzen da. Hala ere, azken bi 
mendeetan prentsen erabilera hedatu da artzainaren lana errazteko. Egurrezko prentsen artean, gehienbat prentsa palankaduna erabili izan da. Aldiz, gaur egungo ekoizpenean, prentsa pneumatiko eta automatikoak dira nagusi.

Amaitzeko, munduko beste leku batzuetako gazta-prentsaketaren inguruko ikerketa-lanik ez dugu aurkitu. Baina, jaso ditugun testigantzen arabera, munduko museoetan aurki daitezkeen tresnak gure arbasoek erabilitakoen oso antzekoak dira.

\section{ESKER ONAK}

Artikulu honen prestaketa-prozesuan lagundu digun jendeari eskerrak eman nahi dizkiogu lerro hauen bitartez: Kabila (Gazta eta Transhumantzia Museoa, Uztarrotze), Unai (Artziniegako Museo Etnografikoa), Elur Ulibarrena (Iruñeko Erresumaren Museo Etnografikoa, Arteta), Batis Otaegi (Gomiztegi baserria, Oñati), Arantza Segurola (Erreizabal baserria, Artzaintzaren Ekomuseoa, Legazpi), Arantxa Gonzalez de Heredia (Txurtxil gaztandegia), Amaia Mujika (Euskal Museoa, Bilbo), Paco Conde (San Telmo Museoa, Donostia), Pello Iriarte (Dorrea elkartea, Arizkun), Fermin Leizaola, Kutxa Fundazioa, MILKARSA (Elgoibar), Ardi SL (Oiartzun), Baionako euskal museoa, eta abar.

\section{BIBLIOGRAFIA}

[1] ALTUNA, J. eta MARIEZKURRENA, K. 2017. Etxekotzearen hastapenak eta bilakaera Euskal Herrian. Animalia etxekotuen europar ikonografia, Eusko Jaurlaritzaren Argitalpen Zerbitzu Nagusia, Gasteiz.

[2] LEIZAOLA, F. eta ARRUGAETA, G. 1999. Gipuzkoako Artzantza, Bertan Saila 13, Gipuzkoako Foru Aldundia, Donostia.

[3] ELORZA, I., ELORZA, L. eta APAOLAZA, J. M. 2006. Zegama, Urbia eta Aizkorriko Artzaintza, Zegamako Udala, Zegama.

[4] MANTEROLA, A. 2001. Ganadería y pastoreo en Vasconia, Labayru Ikastegia, Bilbo.

[5] Nafarroako Gobernua. 2005. Esnea: prozesua eta ohiturak, Nafarroako Gobernua, Iruñea.

[6] VIOLANT I SIMORRA, R. 1997. El Pirineo español (vol. 2), Alta Fulla argitaletxea, Bartzelona.

[7] MATALlANA, S. 1951. Prensado de quesos, Hojas divulgadoras 21-51H, Ministerio de Agricultura, Servicio de Capacitación y Propaganda, Madril.

[8] KINDSTEDT, P.S. The History of Cheese. In PAPADEMAS, P. eta BINTSIS, T. (ed.) 2017. Global Cheesemaking Technology: Cheese Quality and Characteristics, John Wiley \& Sons, Chichester. 
[9] SALQUE, M., BOGUCKI, P.I., PYZEL, J., SOBKOWIAK-TABAKA, I., GRYGIEL, R., SZMYT, M. eta EVERSHED, R.P. 2012. «Earliest evidence for cheese making in the sixth millennium BC in northern Europe». Nature 493, 522-525.

[10] AGUIRRE SORONDO, A., Gazta . Auñamendi Eusko Entziklopedia, Eusko Ikaskuntza. http://aunamendi.eusko-ikaskuntza.eus/eu/gazta/ar-150132/\# hasiera

[11] Normas de calidad para quesos y quesos fundidos, 1113/2006 Errege Dekretua, irailaren 29koa (BOE, 239. zk., 2006 34717-34720).

[12] FOX, P.F., MCSWEENEY, P.L.H., COGAN, T.M. eta GUINEE, T.P. 2017. Fundamentals of Cheese Science, Springer, New York.

[13] International Dairy Federation 2016. Bulletin of the International Dairy Federation 485/2016 - The World Dairy Federation, Brusela, Belgika.

[13] SANDINE, W.E. eta ELLIKER, P.R. 1970. «Microbially induced flavors and fermented foods. Flavor in fermented dairy products». J. Agr. Food Chem. 18, 557-562.

[14] WALTER, H.E. eta HARGROVE, R.C. 1972. Cheeses of the World. Dover Publications Inc., New York.

[15] BURKHALTER, G. 1981. Catalogue of Cheese. Bulletin 141. International Dairy Federation, Brusela.

[16] HARBUTT, J. (ed.) 2009. World Cheese Book. Dorling Kindersley, Londres.

[17] FOX, P.F. eta GUINEE, T.P. «Cheese Science and Technology». In PARK Y.W. eta HAENLEIN G.F.W. (ed.) 2013. Milk and Dairy Products in Human Nutrition: Production, Composition and Health, John Wiley \& Sons, 357.

[18] SIMON, E., RODRIGUEZ, B. eta LABAYEN, I. 2007. Elikagaiak, elikadura eta dietetika, Udako Euskal Unibertsitatea, Bilbo, 129.

[19] ESTORNES, I., Queso. Auñamendi Eusko Entziklopedia, Eusko Ikaskuntza. http://aunamendi.eusko-ikaskuntza.eus/es/queso/ar-105291-78088/

[20] AGIRRE, A. 2009. «Ramon Lizeaga, Antzinako euskal gaztak». Euskonews 479. http://www.euskonews.com/artisautza/0479zbk/arti47901eu.html

[21] LEIZAOLA, F. 2011. «Suero y requesón, productos poco valorados por los pastores vascos». Zainak. 34, 517-528.

[22] FOX, P.F. eta MCSWEENEY, P.L.H. «Cheese: An overview». In FOX, P.F., MCSWEENEY, P.L.H., COGAN, T.M. eta GUINEE, T.P. (ed.) 2004. Cheese: Chemistry, Physics and Microbiology, Volume 1 General Aspects (3. edizioa), Springer Science \& Business Media, Dordrecht.

[23] BLITZER, H. 1990. «Pastoral life in the mountains of Crete». Expedition. 32 (3), 34-41.

[24] WILBEY, R.A, SCOTT, J.E. eta ROBINSON, R.K. 1998. Cheesemaking Practice, Springer, Science \& Business Media, New York.

[25] LAW, B.A. eta TAMIME, A.Y. (ed.). 2010. Technology of Cheesemaking, Wiley-Blackwell, Oxford. 